\title{
CATEGORÍA CASUAL Y FACTOR SEMÁNTICO: EJEMPLIFICACIÓN CON EL ACUSATIVO DE DIRECCIÓN
}

This paper studies some aspects of the relationship between Syntax and Semantics, focusing on the realization of the Accusative in classical Greek. The semantic factor is concluded to be a distinctive feature and, since language is form, as a consequence

Semantics can be expressed by means of discontinuous morphemes.

1. El tema de este artículo es un tema de sintaxis y de sintaxis griega. Pero pronto se observa que la formulación de su título se aparta un tanto de la que aportan los mejores manuales al uso. No voy a hablar de la categoría casual, ni de la categoría modal, ni de las oraciones en forma directa y concreta. Mi propósito, por el contrario, es plantear una cuestión más radical, de lingüistica general y su proyección en algunos apartados de la sintaxis griega. Porque ¿una función sintáctica está sólo marcada por unidades morfemáticas? ¿O debe aceptarse que junto a marcas morfemáticas, como las de caso, de género o de modo, actúan a la vez otros rasgos, o condicionantes semánticos y de comunicación ' que modifican la funcionalidad central de las marcas estrictamente formales?

2. Como es sabido, lo peculiar y relevante de la teoría lingüística moderna ${ }^{2}$, en sus diversas tendencias, radica, por un lado, en la consideración de los aspectos formales, funcionales, de distribución y transformacionales para definir las distintas unidades lingüisticas y, por otro, en prescindir consecuentemente de las dimensiones nocionales y de sus-

1 Desde este punto de vista ya he publicado algunos trabajos: «El factor semántico en la configuración categorial. La gradación del adjetivo como ejemplificación", RSEL 15, fasc. 2, pp. 277-290; «El género en griego clásico. Descripción sincrónica y explicación diacrónica», RSEL 11, fasc. 2, pp. 361-370; "El campo mostrativo ante las diversas funciones del lenguaje", Hahis 3, 1972, pp. 11-28; "Gramática y derivación lexical», RSEL 9, fasc. 2, pp. 63-70.

- Un buen estado de la cuestión respecto a estas propuestas, en G. Serbat, Cas 't fonctions, Paris 1981, con referencia breve a la perspectiva tradicional. Asimismo, G. Mounin, La lingüistica del siglo XX. Madrid 1983. 
tancia de dichas unidades. Es primario ante todo y sobre todo, lo observable; y lo observable, en primera medida, son las formas y, en segunda, su aplicación y realización: perro es de género gramatical masculino porque se opone a perra y en su realización no cabe decir perro blanca. A su vez, chacal, en primera medida, no es ni masculino ni femenino, pues no existe *chacala, pero en su realización cabe decir chacal blanco. Luego se sabe que es del género gramatical masculino por su distribución con otra palabra, en su relación sintagmática.

3. Tal observación tiene la importancia de distinguir estructura y funcionalidad, tantas veces y en tantos autores no clarificadas. Dos estructuras semejantes no comportan necesariamente que la función gramatical de sus elementos sea paralela entre sí. Los modelos estructurales siguientes muestran claramente lo que queremos decir:

1) El lobo persigue al perro / a la perra // a las ovejas

2) El niño escribe al padre / a la madre // a los amigos

Ambas frases ofrecen la misma estructura formal. Sin embargo la función de al perro / a la perra // a las ovejas no es la misma que al padre | a la madre || a los amigos. La prueba radica en la prueba de la conmutación pronominal: supuesta previamente la frase nominal, en 1) puede decirse el lobo lo persigue / la persigue // las persigue, con sustitución de género y número. En cambio, en 2) sólo puede mudar en el niño le escribe // les escribe, donde se respeta exclusivamente el número, pues le sustituye tanto a madre como a padre?.

4. La distinta funcionalidad, por tanto, se proyecta en la estructura superficial mediante la prueba de la conmutación. Pero, asimismo, mediante la prueba de la transformación: el lobo persigue al perro puede transformarse en el perro es perseguido por el lobo. Por el contrario no es posible *el padre es escrito por el niño. De aquí que, pese a que las frases 1) y 2) presentan la misma estructura, en la 1) se dice que al perro | a la perra || a las ovejas son objetos directos y en la frase 2) al padre | a la madre // a los amigos son objetos indirectos. En terminología de E. Alarcos ${ }^{4}$, implementos en 1) y complementos en 2).

5. Estos simples ejemplos conducen a la observación siguiente: que la función sintáctica, formalizada en el plano categorial o paradigmático, no siempre se plasma tal cual y en la totalidad de ocurrencias en el funcionamiento o plano sintagmático, pues la función sintáctica sólo se

${ }^{3}$ Esta perspectiva y los ejemplos mismos los debo a E. Alarcos, Estudios de gramática funcional del español, Madrid 1982, p. 153 ss.

${ }^{4}$ Op. cit., p. 154. 
descubre en la atadura con otras palabras ${ }^{5}$. Por tanto es en el funcionamiento oracional donde ha de encontrarse en su plenitud la función sintáctica.

6. Esta perspectiva está hoy día en el centro de los estudios lingüísticos y de aquí la proliferación de trabajos de gramática funcional. Nombres como Martinet ${ }^{6}$, Christian Touratier ${ }^{7}$, Fillmore ${ }^{8}$ y, con gran influencia, Simon C. Dik ${ }^{9}$, por no citar sino algunos, polarizan la atención de los teóricos del lenguaje. Y la verdad es que se ha clarificado y profundizado en el aspecto funcional del lenguaje, aunque también con cierto olvido del aspecto formal. A lo que se ha denominado significado gramatical o significado morfemático, por oposición a significado lexemático o de la palabra, Simon C. Dik lo estructura en dos niveles ${ }^{10}$ : función sintáctica y función semántica, niveles con autonomía bien marcada.

7. Tomemos los sintagmas siguientes: Juan se pasea; Juan desayuna; Juan recibe un regalo y Juan sufre. No se discute que en todas las ocurrencias Juan sea sujeto, pero en Juan se pasea, Juan es sujeto y además agente; en Juan desayuna, Juan es sujeto y además agente y beneficiario; en Juan recibe un regalo, Juan es sujeto y además beneficiario y en Juan sufre, Juan es sujeto y además paciente. La función sintáctica es ser sujeto; la función semántica es ser agente, paciente, beneficiario, esto es, las nociones tradicionales de finalidad, agente, paciente, dirección, extensión en el espacio y en el tiempo, etc. Para precisar mediante definición, diríamos de una parte que la función sintáctica contempla la perspectiva desde la que se presentan los términos de referencia ${ }^{\prime \prime}$. Touratier, de forma más clara, formula esta definición asi ${ }^{12}$ : «Función sintáctica es la relación puramente construccional y organizadora.» $\mathrm{Y}$, de otra, que la función semántica contempla los referentes de la situación

'A. Martinet, Estudios de sintaxis funcional, Madrid 1978, p. 116: "en la frase el hombre anda, hombre es por naturaleza un sustantivo, y por su función, un sujeto. Aisladamente, hombre conserva su naturaleza pero ya no tiene función: la función es lo que le ata al contexto en el que figura".

Además de Estudios ya citados, cf. El lenguaje desde un punto de vista funcional, Madrid 1971, y La lengüistica sincrónica, Madrid 1968.

7 "Comment définir les fonctions syntaxiques?", BSL 72, 1977, pp. 27-54.

"C. J. Fillmore, "The case for the case", en E. Bach - R. T. Harms, Universals in Linguistic Theory, Londres 1968, pp. 1-88.

$"$ S. C. Dik, Functional Grammar, Publications in Language Sciences, Dordrecht 1978 (en 1983 ya vio la quinta edición); Studies in Functional Grammar, Institute for General Linguistic, Amsterdam 1980; Advances in Functional Grammar, Publications in Language Sciences, Dordrecht 1983.

in Op. cit., 1978, pp. 13 y 18.

1 Así S. C. Dik, 1978, pp. 11, 13 y 18.

12 Art. cit., p. 36. 
o de la cuestión y no de los lexemas ${ }^{13}$. Touratier denomina a esta función semántica "valor semántico" entendiendo por "valor" dimensión gramatical $^{14}$.

8. Esta distinción me parece incuestionable. Pero, al tiempo, se me antoja que se asemeja a un foco que ilumina muy acentuadamente una parcela del escenario, dejando a oscuras gran parte del mismo. En primer lugar la lengua es forma: los constituyentes aparecen en la frase dotados de morfemas y éstos marcan su función. No tienen la misma función canis que canem ni kúwv que кúva, por ejemplo. En segundo lugar, defender la autonomía de la función sintáctica sobre la semántica ${ }^{15}$, no parece correcto. Tal autonomía es más bien de carácter epistemológico, de investigación, mas no real. Se trata de una visión estática del lenguaje: basta observar la multifuncionalidad semántica tal como dirección, extensión, acusativo interno, expresada por un único morfema y dentro de una única función sintáctica de objeto, para adivinar, casi intuitivamente, que en esa multifuncionalidad vive latente una dinámica lingüistica por reducir la disconformidad entre forma y funcionalidad. $Y$ en tercer lugar, resulta cuando menos sorprendente que se hable de función semántica y se prescinda del significado lexemático de los términos; en realidad la función semántica se fundamenta, en muchas ocasiones, en los significados de los constituyentes ${ }^{16}$. Por supuesto que no digo que haya que estudiar la semántica de los constituyentes pero sí digo que hay que tomarla como componente interpretativo ${ }^{17}$ de la función semántica. Ello es lo congruente.

9. Mi tesis, pues, es la siguiente: 1) Que un morfema marca, por sí, la función sintáctica y que para marcar la función semántica asume como rasgo adyacente el componente semántico de los constituyentes. 2) Que, en un momento posterior, ese rasgo adyacente puede formalizarse con lo que el significante morfemático primigenio deja de ser uno e implica una reinterpretación. Esta tesis quiero demostrarla con el análisis del acusativo en griego y en concreto en su función lativa.

10. La doctrina tradicional y común dice ${ }^{18}$, a) que el acusativo ofrece un morfema único y claro y que expresa ya el objeto directo, ya

${ }^{13}$ S. C. Dik, 1978, p. 13.

14 Art. cit., p. 37.

is S. C. Dik, 1978, p. 6.

${ }^{16} \mathrm{Cf}$. aqui, parágrafo 4.

17 N. Chomsky, La linguistique cartésienne, París 1969, p. 63.

${ }_{18}$ Cf. Kühner-Gerth, Ausführliche Grammatik der griechischen Sprache, I, Leipzig 1898, p. 250 ss.; Schwyzer-Debrunner, Griechische Grammatik, II, Munich 1959. p. 67 ss.; P. Chantraine, Grammaire homérique, II. Syntaxe, París 1963, p. 38 ss.; Lasso de la Vega, Sintaxis Griega, Madrid 1968, p. 353 ss. 
significados de dirección, extensión y significado interno; b) que el acusativo de dirección, salvo en Homero y en textos de influencia poéticohomérica, adquiere construcción preposicional, sobre todo con la preposición zis. Kurylowicz ${ }^{19}$, con esa tendencia a la clasificación esquemática, divide los casos en gramaticales y concretos y afirma que la función primaria de aquéllos es sintáctica y la secundaria, semántica y a la inversa, respecto a los concretos. Puesto que el acusativo es caso gramatical, la función de objeto directo, función sintáctica, es primaria y las otras funciones, dirección, extensión e interno, semánticas y secundarias. Es obligado decir que Kurylowicz constata y bautiza ${ }^{20}$ un fenómeno gramatical pero no añade gran cosa a la doctrina tradicional.

11. La cuestión es más compleja. Veamos los siguientes sintagmas:

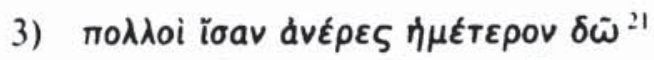

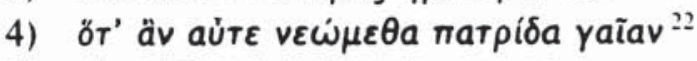

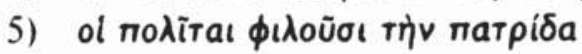

En los tres sintagmas encontramos el mismo morfema casual de acusativo e incluso la misma distribución verbo y complemento en relación inmediata, es decir, sin elemento alguno de enlace ${ }^{23}$. Y sin embargo la función de los acusativos en los sintagmas 3) y 4) no puede ser la misma que la del sintagma 5). En éste se permite la transformación de pasar el acusativo a nominativo sujeto, por tanto, una transformación sin-

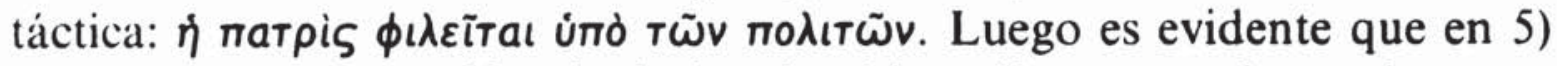
observamos una función sintáctica de objeto directo en el constituyente

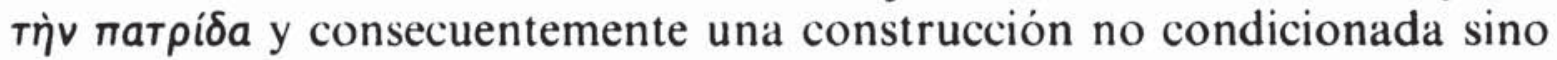
libre: basta colocar el morfema de acusativo a cualquier lexema.

12. En cambio en los sintagmas 3) y 4) no se permite transformación sintáctica alguna $y$, además, provoca, frente a 5), una evolución preposicional muy temprana, lo que indica que su funcionalidad es de otro tenor. Se ha dicho que es acusativo lativo o de dirección, por tanto función semántica. Pero iqué marca, además del acusativo, induce a descubrir que se trata de la función semántica de dirección? Sin duda el componente semántico de sus constituyentes: un verbo de movimiento

14 The inflectional categories of Indo-European, Heidelberg 1964, pp. 179-189.

20) G. Serbat, op.cit., p. 134.

21 Od. I 176.

22 II. VII 335.

"3 A esta característica, "conexión mediata / inmediata", la considera R. Jakobson, Ensayos de lingüistica general, Barcelona 1984, p. 243, como demarcadora entre construcción preposicional y declinación flexional. 
y un sustantivo con significado local ${ }^{24}$. Por tanto, el significante de la función semántica es complejo: morfemático y semántico. Es la situación normal en védico ${ }^{25}$ y residual en latín, tipo ire Romam. Por el contrario, el significante de la función sintáctica es simple y sólo morfemático. Si hemos de ser consecuentes, casi me atrevería a hablar de dos casos diferentes, pues diferentes son sus significantes y diferentes son sus funciones.

13. Pero la lengua es radicalmente forma y tiende, alli donde no se ha alcanzado la total formalización, a dotar de marcas claras las diferentes funciones. Se explica de este modo el tipo noגíns, semánticamente masculino pero morfemáticamente femenino, pues es un tema en $-\bar{a}$, contradicción que se resuelve mediante la sigma. $\mathrm{Y}$ recuérdese el paso de socrus, 'suegra' a socra en el Appendix Probi ${ }^{26}$. No debe sorprender, en consecuencia, que pronto se intentara marcar lingüísticamente la caracterización no totalmente formalizada de la función semántica. Con seguridad en hitita aparece desde el principio marcada esta función de forma morfemática. Laroche ${ }^{27}$ ofrece el ejemplo siguiente:

6) nu weten-a paizzi, "y èl va hacia el agua»

En el lexema weten- $a$ con función semántica de dirección, se observa el morfema $-a$. Sturtevant ${ }^{28}$ postula la idea de que ese morfema - $a$ procede, por sandhi, de la desinencia de acusativo -an, procedente de una forma indoeuropea *-om, sobre todo delante de /s, n, t/, idea que, con alguna variante, ha defendido recientemente Shields ${ }^{29}$.

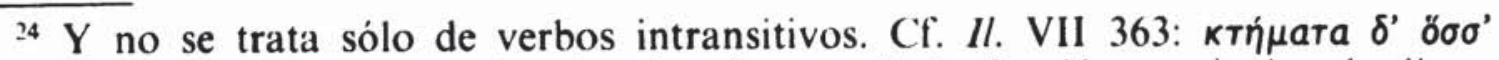

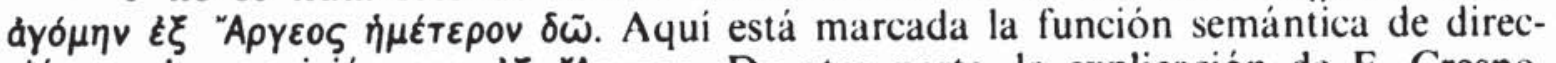

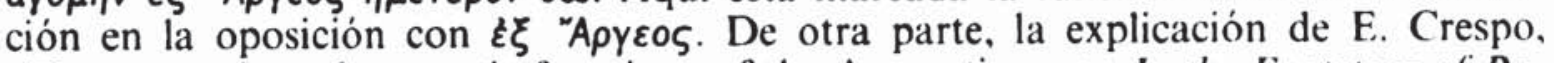
"The semantic and syntactic functions of the Accusative", en In the Footsteps of Raphael Kühner, basada en los fenómenos de coordinación, aposición y yuxtaposición, no es suficiente. Basta tener en cuenta el artículo de P. Kiparsky, "Tense and Mood in Indo-European Syntax", Foundations of Language 4, pp. 30-57, donde se defiende que los segundos miembros de una proposición en general, aunque estén coordinados, marcan una situación más cómoda que la de los primeros.

${ }_{5}$ Cf. J. Haudry, L'emploi des c'as en Védique, Lyon 1977, p. 143. Cf. este ejemplo: sabhám éti kitaváh, "el flautista va a la asamblea».

26 Esta tendencia a conformar morfema y significado gramatical se observa bien en la categoría del género. Cf. Díaz. Tejera, "Sobre la categoría del género gramatical en griego antiguo y algunos problemas morfológicos", EMERITA 39, 1971, pp. 383-424.

${ }_{27}$ E. Laroche, "Études de linguistique anatolienne, III. Le directif», Revue hittite" 't asianique 28 , pp. 22-49.

28 E. H. Sturtevant, "Place Whither in Hittite and the use of proper nouns in the stem forms", Language 5, 1939, p. 146.

${ }_{29} \mathrm{~K}$. Shields, "The Indo-European origins of the old Hittitte Directive Case", Indo-European Studies 10, pp. 273-282. 
14. Esta tesis no ha tenido manifiesta acogida, pero, aunque resulte correcta ${ }^{30}$, no invalida sino que confirma mi postura: se elabora un morfema mediante evolución fonética. Más aceptación ${ }^{31}$ ha tenido la explicación de Laroche: mantiene que este morfema - $a$ representa una $-\bar{o}$ indoeuropea y que implica un morfema propio de dirección, tal cual

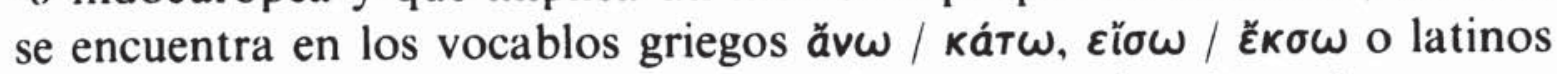
eo / alio. Mas esta explicación no entraña, como quiere Laroche, que ya el indoeuropeo común disfrutara de un morfema de dirección. Más bien, como lo prueba el védico, el griego y latín, que era una tendencia y que esa tendencia se plasma aquí y alli y en cada lengua a su gusto y posibilidades.

15. En hitita esa tendencia es la que vemos realizada. En griego, en Homero, palpamos la lucha por plasmar formalmente esa tendencia. Observemos los siguientes sintagmas:

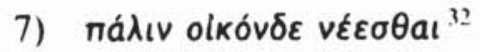

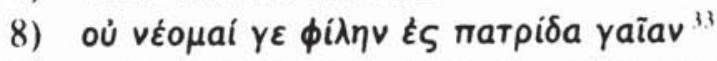

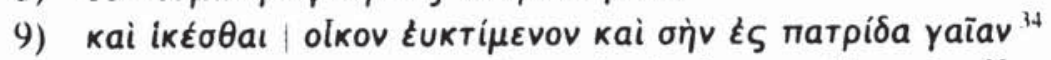

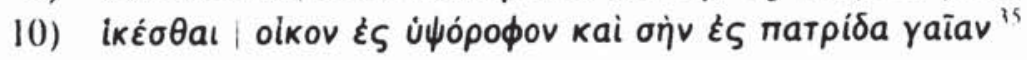

16. En los sintagmas propuestos cabe advertir la formalización de la función semántica de dirección: por un lado, mediante una partícula pospuesta $\delta \varepsilon$ como en 7 ), proceso que quedó abortado y fosilizado en

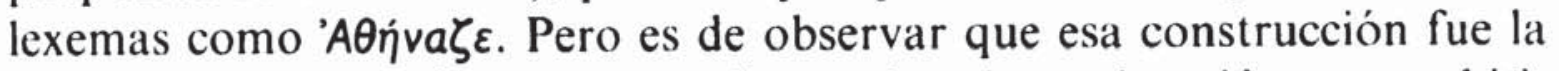
normal en micénico ${ }^{36}$, lo que nos lleva a la misma situación que en hitita $y$, dentro del griego, esta relación con el micénico refleja el mismo comportamiento que la partícula $-\phi \iota$ instrumental. Pero, por otro lado, el ejemplo 9) muestra la coexistencia de la construcción de dirección

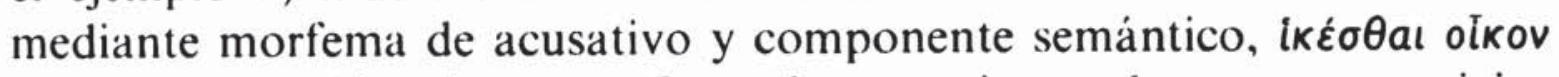
y la formalización plena, morfema de acusativo y elemento preposicio-

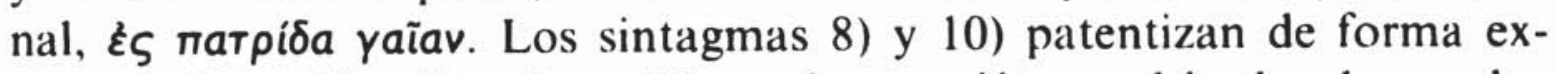
presa la formalización plena. Llamo la atención en el hecho de que los constituyentes lexemáticos son los mismos que en 7) y 9), olkov y патрi$\delta a$. Ello significa que el componente semántico ya no constituye rasgo

30) Compárese $\phi \varepsilon \hat{\rho} \omega$ / hharäm(i), si se acepta tal relación.

"E. Neu, "Einige Uberlegungen zu den hethitischen Kasusendungen", en Hethitisch und Indogermanisch, Innsbruck 1979, pp. 177-196.

32 Il. VI 189.

33 II. XVIII 101.

${ }^{34}$ Od. IV 475.

${ }^{35} \mathrm{Od}$. VII 76.

36 J. Gonda, "The original value of gr. $\delta \varepsilon "$, Mnemosyne 10, pp. 97-102. 
distintivo. Y, como es sabido, esa construcción preposicional es la que se consolida en griego posterior.

17. Mas ¿qué tipo de formalización es el giro preposicional? La doctrina tradicional enseña que la preposición rige y gobierna el caso acusativo y que es la preposición el indicador base de la relación y que el caso se torna una servidumbre gramatical ${ }^{37}$. Pero esta perspectiva tiene el grave inconveniente de considerar la preposición como el morfema absoluto en la relación semántica y ello no es verdad. Basta aducir ejemplos en los que una misma preposición puede construirse con más de una forma casual:

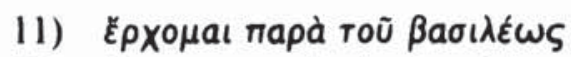

12) Ě

Si la preposición marcara por sí sola la función semántica de relación no habría necesidad de modificar la forma casual. Pero el caso es que, manteniendo la misma preposición, el cambio de forma casual arrastra cambio de significado, "punto de partida» / "punto de llegada». Es más, construcciones latinas ${ }^{38}$ como it in urbem / laborat in urhe provocan una distribución complementaria, de forma que una excluye a la otra, pese a que la preposición es la misma.

18. En realidad tanto monta la preposición como la forma casual. Es decir, se trata de un único significante, sólo que un significante discontinuo, compuesto de dos segmentos de significante. Con otras palabras, se trata de un único morfema con segmentos de significante ${ }^{39}$. Un sintagma como
13) $\varepsilon l \varsigma$ патрі́бa
14) in urbem

habria que analizarlo ${ }^{40}$, desde el punto de vista morfemático, como els $+-a$ e in + -em en el caso latino. Desde esta perspectiva, dos conclusiones son incuestionables: una, que no hay rección, sino implicación, esto es, implicación mutua de dos segmentos de significante. Y la otra conclusión ya expresada: que el acusativo preposicional es un caso y el acusativo morfemático otro caso distinto, pues distintos son sus morfemas y distintas sus funciones. El morfema discontinuo proyecta función

${ }^{37} \mathrm{~J}$. Perrot, "Le fonctionnement du système de cas en latin», $R P h$ 40, pp. 217-227.

3* Touratier, "Accusatif et analyse en morphèmes", BSL 74, pp. 50-92.

19 Touratier, "Accusatif», p. 48.

40) J. Kurylowicz, Le probleme du classement des cas. Esquisses linguistiques, I. Munich 1973, pp. 134-135. 
semántica de dirección, el morfema casual proyecta función sintáctica de objeto directo. No hay, pues, sincretismo de funciones ni funciones primarias y secundarias. Y, por supuesto, no se me oculta que esta segunda conclusión pueda sorprender. Pero el razonamiento obliga a ello.

19. Pero no es esto todo. Cabe la pregunta de por qué es el acusativo y no otro caso el que asume la función semántica de dirección. Podría responderse que, dada la evolución que hemos descrito, no podía haber otra salida: un acusativo sin preposición ayudado por el componente semántico ya expresaba dicha función. Consúltese sintagmas 3) y 4). Mas ello es retrotraer la respuesta, porque en esa construcción cabe la misma pregunta. La contestación debe venir de un análisis diferente. Brevemente, veamos los siguientes sintagmas:

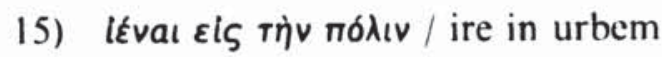

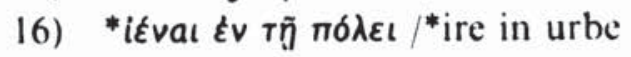

Las construcciones de 15) con acusativo son correctas. Pero el hablante, si emplea un verbo de desplazamiento, no puede emplear la construcción de 16), con dativo o ablativo. Si se da el componente semántico de desplazamiento, el acusativo de dirección no es conmutable con otro caso. Es decir, un componente semántico como léval / ire, excluye una construcción de lugar "en donde» como sustituto.

20. En cambio el locativo, si no puede darse como sustituto, sí como acompañante. Es correcto decir:

17) En la ciudad fui a la asamblea

18) in tempore ad eam ueni ${ }^{41}$

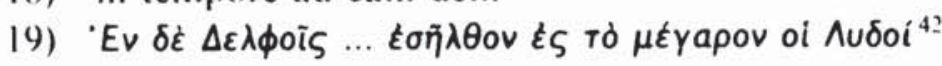

Ya Kurylowicz hizo la observación de que el acusativo de dirección es más central que el locativo ${ }^{43}$. Es una intuición correcta y que encuentra una formulación cientifica en la gramática dependencial o de valencias tal como se ha estudiado por Tesnière ${ }^{44}$, Happ ${ }^{45}$ y Touratier ${ }^{46}$. En efecto, de los constituyentes inmediatos adjuntos al verbo, unos son necesarios, exigidos por el propio significado del verbo, mientras que otros

"Ter., He'aut. 364.

4. Hdt. I 47.

4' Le prohlime'... pp. 13.3-134.

${ }^{44}$ L. Tesnière, Eleme'nts de sintaxe structurale, París 1965.

45 H. Happ, Grundfragen einer Dependenz-Grammatik des Lateinischen, Gotinga 1976. Importante es su articulo «Syntaxe latine et théorie de la valence. Essai d"adaptation au latin des théories de Lucien Tesnière", Ét. Class. 45, pp. 337-366.

th Ch. Touratier, "Comment définir...", pp. 4()-43. 
son periféricos, circunstantes y expansivos, no imprescindibles para la construcción oracional. En terminología de L. Bloomfield ${ }^{47}$ construcción exocéntrica en el primer caso y endocéntrica en el segundo.

21. Desde este enfoque, resulta claro que en los sintagmas mencio-

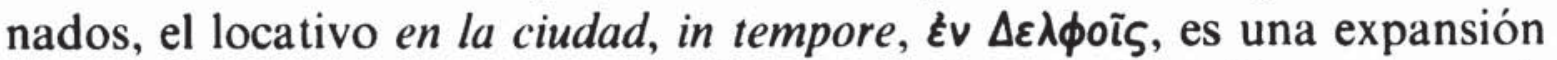
no exigida, mientras que la función semántica de dirección es una adjunción necesaria, una vez puesto el verbo de movimiento. $Y$ si algún complemento ofrece rasgo necesario, es el de objeto directo. Luego no es por azar, primero, que la función semántica de dirección se haya asentado en el caso acusativo y, segundo, que se explique que no pueda haber conmutación con otros casos pues pertenecen a dimensiones diferentes. Pero de este último análisis, la conclusión más interesante es la siguiente: que la función semántica de dirección, marcada por el componente semántico y significante discontinuo, está en la misma relación directa y de transitividad que la función sintáctica de objeto directo con su verbo ${ }^{48}$. Ambas construcciones son exocéntricas. Sólo que el componente semántico y la tendencia a la formalización han marcado caminos distintos.

\section{A. Diaz Tejera}

47 Language, Nueva York 1933, pp. 194 ss. y 235 ss.

${ }^{4 *}$ Ch. Touratier, "Accusatif...», pp. 55-56. 